\title{
La guerre est finie y/o ¿La guerra ha terminado?: El filme de Alain Resnais y Jorge Semprún y su papel en la exposición permanente del Centro de Arte Reina Sofía
}

\author{
Maureen Tobin Stanley \\ University of Minnesota, Duluth \\ mtobinst@d.umn.edu
}

\begin{abstract}
This article analyzes the ambiguity in the film La guerre est finie ([The War Is Over] 1966, director Alain Resnais, screenwriter Jorge Semprún) whose declarative title becomes a question in the title of the permanent exhibit at the Reina Sofía National Museum in Madrid: Is the War Over? Art in a Divided World (19451968). The works invite the viewer to question the nationalism that catapulted the Spanish Civil War, whose victory marked the first triumph for European fascisms and concomitant genocides. While the film entirely lacks symbols of irrefutable national identity, the paintings incorporate and subvert certain
\end{abstract}


icons of (regional, Francoist, Nazi or Fascist) nationalism, as well as emblems of the Spanish Republic and Spain. The artworks respond in theme and form to nationalist ideology and esthetics. Although the film-whose screenwriter Jorge Semprún had been imprisoned in the Nazi camp at Buchenwaldlimits itself to implicit allusions to the eradication of the domestic enemy on Iberian soil and the so-called stateless undesirables exiled in foreign lands, the exhibit explicitly references Nazism and other 20th-century genocides. The collection of works exemplifies Aharon Appelfeld's assertion: that only art has the ability to redeem suffering from the abyss. The film and the plastic works respond not only to nationalist ideologies and concomitant lived and witnessed experiences, but also to nationalist art. Through the visual counternarratives that give voice to myriad victimizations, these works make manifest and denounce, in theme and form, the anti-intellectualization and the fervent sentiment of political zeal.

Keywords: Fascism; Nationalism; Spain; Jorge Semprún; Alain Resnais; Museo Nacional Centro de Arte Reina Sofía; Juan Genovés; Antoni Tàpies; Eduardo Arroyo; exile; genocide

\section{Resumen}

En este artículo, se analiza la ambigüedad en el film La guerre est finie (1966, dirección Alain Resnais, guion Jorge Semprún) cuyo título declarativo se transforma en una gran interrogativa al ser el título de la exposición permanente en el Museo Nacional Reina Sofía: ¿La guerra ha terminado?: El arte en un mundo divido (1945-1968). El propósito de las obras es hacer que el espectador cuestione el nacionalismo que dio pie a la guerra civil española y triunfó, así constituyendo la primera victoria para los fascismos europeos y concomitantes genocidios. Mientras la película carece casi por completo de signos de identidad nacional inconfundible, las pinturas incorporan y subvierten ciertos íconos del nacionalismo (sea regional o franquista, nazi o fascista) además de emblemas de la República o de lo español. De ahí responden en tema y forma a la ideología y la estética nacionalistas. Aunque el filme-cuyo guionista Jorge Semprún estuvo preso en el campo nazi en 
Buchenwald-alude implícitamente a la erradicación del enemigo doméstico en suelo ibérico y los apátridas indeseables en tierras ajenas, la exposición explicita el empeño nazi y otros genocidios del siglo XX. El conjunto de obras del edificio Sabatini ejemplifica la afirmación de Aharon Appelfeld: que solo el arte tiene la capacidad de redimir el sufrimiento del abismo. El filme y las obras plásticas responden no sólo a las ideologías nacionalistas y las concomitantes realidades vividas y presenciadas sino también al arte nacionalista. Mediante la contranarrativa visual, al dar voz a una miríada de victimizaciones, estas obras ponen de manifiesto y denuncian, en tema y forma, la desintelectualización y el sentimiento ardiente del celo político.

Palabras Clave: Fascismo; Nacionalismo; Jorge Semprún; Alain Resnais; Centro de Arte Reina Sofía; Juan Genovés; Antoni Tàpies; Eduardo Arroyo; exilio; genocidio

"Only art has the power of redeeming suffering from the abyss"

-Aharon Appelfeld

\section{Introducción}

E I primero de abril de 1939 en el último parte de la Guerra Civil, el generalísimo Francisco Franco proclama en mayúscula, "LA GUERRA HA TERMINADO". En 1966, Jorge Semprún y Alain Resnais estrenan el film La guerre est finie, sobre la resistencia clandestina, ironizando así la proclamación del Caudillo. En 2010 la exposición de arte titulada ¿La guerra ha terminado?: El arte en un mundo dividido (1945-1968) fue inaugurada en el Museo Nacional Centro de Arte Reina Sofía [MNCARS] para el vigésimo aniversario del museo y forma parte de la colección permanente. Las obras de la colección, de artistas de todo el globo,' tratan directa e indirectamente el tema de la guerra y la autocracia, abarcando la Guerra Civil Española, la Segunda Guerra Mundial, las guerras en Asia, la Guerra Fría, además de los regímenes y conflictos en 
Latinoamérica, Europa, África y Asia entre otros. ${ }^{2}$ De las salas dedicadas a la exposición, me centraré en solo cuatro obras de los años 60, seleccionadas por ser de reconocidos artistas españoles coetáneos de Semprún y por ostentar un vínculo con el autor madrileño o por estar posicionados en relación a la instalación fílmica La guerre est finie. Las cuatro obras son Blau amb quatre barres roges de Antoni Tàpies (1966, pintura: óleo y arena sobre lienzo, 169,9 x 195,3 cm); La puerta de Juan Genovés (1966, técnica mixta sobre lienzo, 140 x $90 \mathrm{~cm}$ ); Los cuatro dictadores de Eduardo Arroyo (1963, cuadríptico: óleo sobre lienzo, 235 x 140 cm cada pieza) y España te miró de Eduardo Arroyo (1967, óleo sobre lienzo, $150 \times 150 \mathrm{~cm}$ ).

Blau amb quatre barres roges, ${ }^{3}$ del artista catalán Tàpies, alude implícitamente a la deportación de los republicanos a los campos nazis. Los cuatro dictadores, en la sala 428 , constituye un preludio directo a la sala 429, titulada "La guerra ha terminado", donde, cuando se realizó este estudio, se ubicaban el filme de Resnais y Semprún, La puerta y España te miró. ${ }^{4}$ El diálogo intertextual entre el filme y la exposición-ejemplificada por las cuatro obras-subvierte tanto la estética como la temática del arte nacionalista y, por ende, presenta una denuncia de la dictadura posbélica y su concomitante represión. Además, en las llamadas guerras de la memoria de la España contemporánea, ${ }^{5}$ dicho diálogo intertextual constituye un recordatorio de la pluralidad de perspectivas con respecto al pasado. El trauma colectivo refleja la libertad de pensar y de dar voz a la crítica. Al incentivar la diversidad de miradas críticas, la exposición de arte (anclada en el filme) subvierte el deshumanizante monolitismo ideológico y estético.

Desde los estudios del Holocausto, es posible reafirmar que la representación culturaljya sea arte, cine, o literatura-genera un espacio psíquico e intelectual desde el que indagar y descifrar un fenómeno carente de sentido. En este estudio veremos que la colección impugna el intento de las ideologías deshumanizantes de conferir significado a la aniquilación de 
la humanidad y revela el vacío y el engaño de la autocracia. Refutando las polaridades de verdad objetiva versus memoria explayadas por críticos como Santos Julià, Sebastiaan Faber advierte de los peligros de los discursos sobre el pasado basados en oposiciones binarias como, por ejemplo, el objetivismo vs. el subjetivismo, lo interesado vs. lo desinteresado y la verdad vs. la falsedad, ya que la supuesta objetividad inventa el mito de una lectura única en vez de concretizar una realidad compleja, completa, multifacética y poliexperiencial (15). Según Alejandro Baer y Natan Sznaider los estudios del Holocausto y el trauma en torno a la política de la memoria han concientizado a toda una generación de eruditos, artistas y escritores. Como resultado, la memoria histórica "is [...] tied to developments connected to the impact in Spain of a globalized Holocaust discourse" (66). La colección en el MNCARS provoca múltiples miradas al discurso globalizado del genocidio. No inculca ninguna perspectiva única, sino que el empeño es la intelectualización autónoma por parte de cada espectador, que ha de encarar a principios del Siglo XXI las guerras y los genocidios de mediados del Siglo XX y su legado. ${ }^{6}$

La guerra llega a ser un apocalipsis personal, familiar y social. La guerra traumatiza, mutila y desmiembra. La memoria y el acto de rememorar han de constituir la contranarrativa a la desmembración del trauma bélico. La guerra es homicida, sea fratricida o genocida: la muerte es un final. En este ensayo propongo analizar la ambigüedad y el cuestionamiento del final del conflicto bélico en el film La guerre est finie (1966, dirección Alain Resnais, guion Jorge Semprún) y en particular cómo este film cuyo título declarativo, La guerre est finie (La guerra ha terminado), se transforma en un gran interrogante como título de la exposición permanente en el MNCARS en Madrid: ¿La guerra ha terminado?: El arte en un mundo divido (1945-1968). Tanto el filme como la exposición constituyen una paradoja y desestabilizan el paradigma binario del comienzo y el final, de un antes y un después, de la guerra y la paz. El propósito de las obras es hacer que el espectador cuestione, entre otras realidades, el 
nacionalismo que dio origen a la guerra civil española y triunfó, constituyendo así la primera victoria para los fascismos europeos y concomitantes genocidios de los años 40. Saldrá a relucir que mientras la obra de Semprún carece casi por completo de signos de identidad nacional inconfundibles, las pinturas que seleccioné incorporan y subvierten ciertos íconos del nacionalismo (sea regional o franquista, nazi o fascista) además de emblemas de la República o de lo español, como La maja desnuda de Francisco de Goya recontextualizada. Así, estas obras responden en tema y forma a la ideología y la estética nacionalistas.

El título del filme no sólo se emplea (ironizado y subvertido) para dar nombre a la exposición, sino que también, de manera reveladora y provocadora, la película en blanco y negro constituye la última parada-el final del trayecto-para los visitantes a la galería y la exposición. Cabe decir que el filme llega a ser más que una obra cinematográfica en sí. Desempeña un papel polivalente que incluye el de ser una pieza de arte, una "instalación”, lo cual crea una nueva experiencia para el espectador cuyo trayecto culmina en un banco donde puede quedarse sentado por el tiempo que desee, bien para empezar a entender y profundizar en las complejidades de la exposición o para finalizar su experiencia con el segmento del filme que le toque. Tanto el filme de Resnais como la exposición del Reina Sofía desmienten y a la vez respaldan el concepto de finalización, mientras cuestionan la esencia de las ideologías deshumanizantes. El filme subraya que, mientras que la guerra (o sea la contienda armada en el campo de batalla) terminó el 10 de abril de 1939, la lucha clandestina a los dos lados de los Pirineos siguió vigente casi tres décadas después de la llamada "Victoria". De forma paralela, la exposición pone de manifiesto y al mismo tiempo critica la universalidad del fenómeno bélico que brota del imperialismo, el totalitarismo, y el deshumanizante espíritu conquistador. Centenares de guerras empiezan y supuestamente terminan, pero los efectos devastadores no concluyen, los traumas provocan amargura, 
tristeza, la pérdida de inocencia y la desconfianza además de, en ciertos casos, dar pie a más violencia y odio. La prevalencia de la guerra (que se extiende por la faz de la tierra sin diferenciar entre razas, clases o actitudes políticas, según revelan las mil obras que ocupan las 29 salas de la exposición) apunta al hecho de que la guerra, y la violencia que genera, es eterna e infinita. Mientras que el filme, cuyo guionista, Jorge Semprún, estuvo preso en el campo nazi en Buchenwald, alude implícitamente a la erradicación del enemigo doméstico en suelo ibérico y los apátridas indeseables en tierras ajenas, la exposición explicita el empeño genocida nazi y su incontrovertible evidencia repetida y emulada ad infinitum a lo largo del siglo XX. El conjunto de obras en la cuarta planta del edificio Sabatini ejemplifica la afirmación de Aharon Appelfeld de que solo el arte tiene la capacidad de redimir el sufrimiento del abismo (Kaplan 1). Según asevera Kaplan en Unwanted Beauty: Aesthetic Pleasure in Holocaust Representation, aunque un documental histórico no afecte profundamente al espectador, el poder estético del arte (como la literatura, los memoriales y el cine) "encourages [readers and viewers] to remember the Holocaust rather than to shunt it aside" (2). A través del presente estudio se puede discernir cómo el filme y las obras plásticas españolas que seleccioné responden no sólo a las ideologías nacionalistas y las concomitantes realidades vividas y presenciadas, sino también al arte nacionalista y, en particular, franquista. Mediante la contranarrativa visual, al dar voz a una miríada de victimaciones, estas obras ponen de manifiesto y denuncian, en tema y forma, la desintelectualización y el sentimiento ardiente del celo político.

\section{El arte en la literatura de Semprún y la función de Semprún en el arte}

En su estudio "The Significance of Art in Semprún's Writing", Tijana Miletic subraya la estrecha relación que tenía el autor con la pintura, particularmente las del Prado, el cual frecuentaba de niño cuando vivía a sólo cien metros del museo (169). De joven encontraba serenidad en las galerías. Además, según 
explica Miletic, el Museo del Prado llegó a ser "a safe space or hideout of sorts during his years as 'Federico Sánchez,' the clandestine anti-Francoist agent working in the underground in 1950s Madrid [...1]t also informs the creation of the museum as a space of respite as well as intrigue for one of Semprún's alter egos, the Soviet spy Ramón Mercader in La deuxième mort de Ramón Mercader" (169). Para Miletic, las funciones solapadas del arte y las exhibiciones en la literatura sempruniana son cuadripartitas: la función narrativa (de reflejar el argumento en la narrativa visual del cuadro), la función estética, la función psíquica (en que el correlativo objetivo visual permite que el personaje sobrelleve las dificultades de su vida) y la función política. Respecto a la función política del arte en la literatura sempruniana, Miletic asevera que "[by] using the painting as a historical object whose past must be brought into the political conversation about the present [...art provides] an erudite commentary on the dynamics of power and theories of spectatorship, culminating in the critique of overbearing [...] powers" (170).

No ha de sorprender, por consiguiente, que el MNCARS celebrara su vigésimo aniversario con la inauguración de la exposición ¿La guerra ha terminado? y la arraigara en el filme de este autor y guionista, ex-deportado y antiguo Ministro de Cultura, cuyas obras subrayan el valor del arte y el despertar de la conciencia que resulta de su contemplación. Curiosamente, si, según las teorías de mimesis, el arte imita la vida, se ve algo curioso en el caso de Semprún. En su literatura el arte literario imita el arte plástico. O sea, Semprún incorpora el arte como un punto de partida de la reflexión. Sin embargo, el contexto artístico, es decir, el conjunto de las casi mil obras, comparte espacio en la exposición con el arte literario y fílmico del autor madrileño a través de la temática y concomitante denuncia del trauma, la violencia y el genocidio. Por ende, la exposición que alude a Semprún también tiene las mismas funciones, expuestas por Miletic, que la literatura sempruniana, la cual alude al arte. Como lectores y espectadores del arte y del filme, podemos percibir 
ciertas semejanzas. ¿La guerra ha terminado? ostenta una función narrativa (en que cuenta múltiples y solapadas historias), es estética, permite el proceso psíquico de enfrentar y sobrellevar el trauma y, finalmente, desempeña un papel político. En "The Trauma of History/ The History of Trauma: Plotting Memory in Jorge Semprún”, Kathleen Vernon examina la interacción entre la temática del trauma y la forma traumática que realiza Semprún con el fin de testimoniar (158-62). Sus obras están repletas de anomalías y múltiples estratos temporales, "endless dilations in the narration of individual events [...] the embedding of diverse incidents and digressions in the style [...] within the account of another event discontinuous in time and space [...] accompanied by spatial distortions" (159). Igual que en las obras de Semprún, el conjunto de obras en las galerías (de vertientes desmesuradamente dispares y que abarcan el informalismo y la representación política española de los 60, el cine hollywoodense de los 50 y el modernismo internacional, entre otras) representan el trauma como temática (violencia, genocidio, sufrimiento, exilio, injusticia), pero también en sus aspectos formales (fraccionamiento, desintegración, rotura, abstracción, palimpsestos). Como resultado se abre una conversación con respecto al presente y su relación con el pasado traumático con el fin de analizar las dinámicas del poder.

\section{El nacionalismo y sus símbolos: Estética e ideología y la subversión artística}

La exposición de arte no se puede considerar en un vacío. En particular responde al nacionalismo tanto en la temática como en la estética. El arte nacionalista, según Ángel Llorente en Arte e ideología en el franquismo (1936-1951), se divide en tres etapas. La primera abarca desde 1939 hasta 1941 y propaga la monumentalización del Glorioso Alzamiento e imitación de la estética y la ideología del nacionalsocialismo alemán (93), las cuales se difundían mediante publicaciones como Nueva España y La Vanguardia Española (99). La segunda 
(1941-1945) gira en torno a la modificación en la Sección de Plástica que se subsume a la Delegación Nacional de Propaganda (107). La tercera (1945-1952) resulta de la derrota de las fuerzas del eje en la Guerra Mundial. Llorente capta la transformación de la siguiente manera: "el régimen se fue desprendiendo de la simbología fascista que aún mantenía y que le relacionaba con la iconografía y el ritual de los derrotados. Entre otras medidas recordemos la supresión del Saludo Nacional" (112). El arte de estas etapas era militante; se enfocaba en el espectador y aspiraba a evocar en este el celo ardiente y la pasión colectiva por la nación.

A diferencia del arte franquista, ni La guerre est finie ni ¿La guerra ha terminado? tienen la intención de evocar pasión ni sentimiento, sino que se distinguen por dos características: primero, apelan al intelecto, y segundo, no buscan ninguna reacción concreta, sino que ponen en marcha un proceso, una experiencia subjetiva. Así pues, la gran distinción yace en que el arte franquista circunscribe un resultado definitivo, mientras que la exposición alienta un proceso (mediatizado por el razonamiento crítico y la intelectualización).

Para Manuel Borja Villel, Director del MNCARS, la exposición permanente se concibió como una respuesta, el comienzo de un diálogo a una época polarizada, entre dos ideologías de dos hemisferios geopolíticos. La guerra civil española llegó a ser un ensayo general para la segunda guerra mundial, la cual resultó en el nuevo equilibrio de poder y la creación de una sociedad de consumo que transformaron la percepción del mundo; de ahí, afirma Borja Villel, la creación del arte se mueve entre el representacionalismo y la abstracción individualista (Borja Villel 5).

Cuando se inauguró la exposición en el 2010, el recorrido arrancaba de manera explícita con dos obras sobre el nazismo: Monument aux espagnols morts pour la France (1946-1947) de Pablo Picasso y el filme de Alain Resnais Nuit et brouillard (1955). El óleo sobre lienzo $(195 \times 130 \mathrm{~cm})$ de Picasso retrata una escena que linda en doméstica. A primera vista da la impresión de una 
chimenea decorada, una estatua, dos plantas y una alfombra. Si se mira con detalle, dos macetas flanquean una alfombra que sirve de plataforma para el "monumento", que parece un posible busto laureado de Napoleón, con el brazo derecho alzado en saludo. El busto está rodeado de la tricolor gálica. La alfombra ostenta una calavera y tibias cruzadas, ínfimo emblema del nazismo. La placa que da nombre al cuadro, "Aux espagnols morts pour la France”, denuncia la complicidad y culpabilidad franco-germana con respecto a los españoles (particularmente los republicanos) que murieron en la lucha antifascista al otro lado de los Pirineos. De modo parejo en la denuncia del fascismo, el icónico filme capta las espeluznantes imágenes de la liberación de los campos en abril y mayo de 1945. La película de Resnais capta en celuloide las macabras realidades de la falta de vida y la muerte dentro de las alambradas del universo concentracionario. Los punzantes planos cortos yuxtapuestos con los largos de los que habían sido seres humanos imbuyen (por su proximidad física en la galería) sensibilidad visceral a la frialdad cubista e intelectual del óleo de Picasso. Resulta lógico, y de hecho circular, que la exposición arranque con un filme de Resnais y clausure con otro. No sorprende que Resnais, autor de Noche y niebla, y Semprún, ex-deportado, colaborasen en La guerre est finie. Las obras de Jorge Semprún (Madrid, 1923-París, 2011), exploran el desarraigo, el desasosiego, el despoje de nacionalidad y la pérdida de la patria, además de la lucha ideológica, el cuestionamiento de identidad personal y nacional que trasciende el trauma bélico.

Como he indicado en otra publicación la transitoriedad perenne se destaca en el guion/filme La guerre est finie (Tobin Stanley). Todas estas escenas de transporte, tránsito y sobre todo el desplazamiento apuntan a un hecho clave: que la guerra, el desarraigo y la dictadura contribuyen a un final al que nunca se llega, pero también a un comienzo que nunca termina de empezar. Es un estado de limbo, de desarraigo sin dar pie al arraigo. En 1966 se estrena el filme de Resnais, La guerre est finie, en el que Semprún, como guionista, 
abordaba la infatigable lucha clandestina del partido comunista a ambos lados de los Pirineos además del desengaño con el partido comunista. Según explica Françoise Nicoladzé en La deuxième vie de Jorge Semprún, el propósito de Semprún es el de comprometer a su lector con "la Historia [con mayúscula] y la lucha contra las fuerzas de opresión" (13)..$^{7}$ En su estudio de tres guiones semprunianos, Txetxu Aguado afirma que

Semprún chooses a voice that addresses political ailments as manifestations of concrete historical configurations. History [...] is the result of power and its entanglements. Violence, in the form of Nazism, the Francoist genocide, or the $[\ldots]$ questionable democratic practices in liberal and communist societies, obeys a rationale that is political and contingent. For [Semprún...] acknowledging the true nature of history requires a moral/ethical and political initiative, one that guides us through the past with a pedagogical purpose. (187)

Discrepo de Aguado en cuanto al propósito pedagógico, que lindaría en pedantería y supremacía intelectual. En vez tildar la intención de Semprún de didáctica, opino que el filme y, por extensión, la exposición no pretenden enseñar lo que uno tendría que saber o pensar, sino que invitan al espectador a razonar para llegar a sus propias conclusiones-repletas de contundentes complejidades.

Las obras que tratan el tema del exilio, como La guerre est finie, exploran la búsqueda de identidad del individuo desplazado, obligado a vivir las ambigüedades causadas por fuerzas históricas fuera de su control. En A Critical Companion to Jorge Semprún, Ofelia Ferrán y Gina Herrmann consideran el corpus literario del autor como autoficción, lo que Serge Doubrovsky denomina la fusión fluida de lo fictivo y lo autobiográfico en busca de uno mismo (11n35). De modo semejante, con respecto a la/s identidad/es transnacional/es, según Homi Bhabha, el derecho a narrar posibilita una búsqueda de identidad 
nacional o comunitaria dentro de un contexto global que reinscribe la experiencia del sujeto a la historia transnacional (Bhabha xx). Al desestabilizar el paradigma centro-margen (o sea los nacionalismos hegemónicos versus los enemigos domésticos o apátridas), la temática de la obra de Semprún imposibilita el binarismo jerarquizado y fomenta el razonamiento crítico. De modo semejante, la prevalencia de imágenes intersticiales en La guerre est finie ejemplifica las ideas de Bhabha, según las que "temporal movement and passage [...prevent] identities at either end from settling into primordial polarities. This interstitial passage between fixed identities opens up the possibility of cultural hybridity that entertains difference without an assumed or imposed hierarchy" (5). Lo intersticial, los conceptos y las imágenes de estar "entremedias"-lo que Bhabha denomina "in-betweenness"-constituyen el Tercer Espacio que desmiente todo binarismo y revela la realidad matizada que desmiente el absolutismo. A saber, el lema franquista de "Una, Grande y Libre" se revela imposible a la luz de varios factores del filme: la resistencia, la condición de apátrida, las múltiples identidades, el perfecto bilingüismo, además de las imágenes concretas que refutan el binarismo de "aquî" o "allá". Así, mediante la prevalencia de las imágenes intersticiales en La guerre est finie, Resnais y Semprún captan la verdad esencial del legado de la guerra y el cuestionamiento de la identidad.

La guerre est finie comienza en abril de 1965 con un refugiado español, revolucionario profesional (protagonizado por Yves Montand) cuyas múltiples identidades (Carlos, René, Domingo, Gabriel Chauvin y Diego Mora) ponen en tela de juicio su identidad. Diego regresa a Francia después de haber realizado los preparativos para una huelga general en España cuyo fin era derrocar a Franco. En la secuencia de apertura, en la frontera franco-española en el Puente Behobie, resalta la alienación del Pasajero (alias Diego) y lo que Bhabha denomina la interacción: "it is the space of intervention emerging in the cultural interstices that introduces creative invention into existence [... 
P]erformance of identity as interaction [is] the re-creation of the self in the world of travel, the resettlement of the borderline community of migration" (Bhabha 12). El Pasajero y el Conductor están en el coche filmados en planos cortos a veces a través del vidrio. En el primer encuadre tras el cristal, el Pasajero está en el interior del coche mientras la mirada del espectador se origina en el exterior. Otro plano revela la perspectiva del Pasajero, que observa la frontera-símbolo del "in-betweenness"-a través del parabrisas. La cuestión lingüística y la escurridiza identidad franco-española también revelan el espacio “entremedias”. Recalca Bhabha, “'in-between' spaces provide the terrain for elaborating strategies of selfhood-singular or communal-that initiate new signs of identity, and innovative sites of collaboration, and contestation, in the act of defining the idea of society itself" (Bhabha 2). El Conductor aplaude el perfecto bilingüismo del Pasajero: "al oírte hablar, nadie creería que fueras español". ${ }^{8}$ De manera paralela, Diego se inmiscuye en medio de dos intereses eróticos: Nadine, una revolucionaria veinteañera, y Marianne, la pareja de Diego de hace años que aspira a recuperar la normalidad doméstica: una familia en España con un marido no revolucionario. El sinfín de situaciones ambivalentes y espacios intersticiales (el aeropuerto, puentes, la estación de ferrocarril, coches, la Isla Saint Louis en el Sena, caminatas apresuradas por la calle, escaleras, umbrales) da constancia del desarraigo y el tercer espacio que hace añicos, no solo los binarismos antitéticos (relación estable-desliz, nosotros-ellos, vencedores-derrotados, francés-español), sino también la identidad como una construcción monolítica y monológica. Diego, como revolucionario cuarentón y apátrida, dista mucho de su amante francesa y veinteañera Nadine, miembro del colectivo leninista "Acción Revolucionaria", compuesto de hijos de españoles exiliados y universitarios franceses. Tampoco encaja en la organización clandestina de españoles en París, ya que reconoce la ineptitud y el alto riesgo de sus estrategias. Tras una serie de intrigas, Diego sale para Barcelona a emprender lo que podría ser su última misión. Los 
últimos planos enmarcan a Marianne corriendo en el aeropuerto para advertir a su amante del inminente peligro que corre. Las imágenes intersticiales de aeropuertos, estaciones de trenes, amores pasajeros y transeúntes confirman la interacción y reflejan lo que la voz en off denomina "el pequeño universo de exilio" (La guerre 51, 52), o sea la realidad posbélica para medio millón de españoles.

En las obras de Semprún los conceptos de patria, patriotismo y repatriación reflejan una especie de desengaño teñido de nostalgia. En La guerre est finie, cuando su amigo Bill menciona España de paso, Diego responde con vehemencia: “Pobre España infeliz, heroica España. Estoy harto de España, más que harto. España ha llegado a ser un mito para los combatientes del pasado [...] España no es más que el sueño del turista o el mito de la guerra civil. España ha dejado de ser el sueño del 36" (93-94). ${ }^{9}$ Cabe decir que Diego, ya desengañado, encara el romanticismo fracasado de casi media vida de clandestinidad.

En este sentido el último alias de Diego, Gabriel Chauvin, resulta revelador. Gabriel es el ángel de la anunciación, que vaticina la redención, la salvaciónposiblemente la liberación. El apellido Chauvin alude a Nicolas Chauvin, el legendario soldado del primer ejército de la República Francesa, satirizado en la literatura por su fervor patriótico. Ahora bien, este nom de guerre Gabriel Chauvin apunta a varios elementos: Diego viaja a Barcelona, pero no anunciará la inminente salvación ni liberación de nadie, sino que su viaje presagia un nefasto fin para él y su colectivo revolucionario, tanto en el exilio como en España. El apellido de Chauvin arroja luz sobre una ideología quijotesca y da pie al cuestionamiento del patriotismo mismo. A pesar de presentar el desengaño y las repercusiones del fervor, el propio Semprún, a los 80 años, asevera, "Si ningún pueblo, sociedad, grupo, minoría, hubiera arriesgado la vida por la libertad, la justicia o la fraternidad, seguiríamos en una sociedad esclavista o no habríamos salido del despotismo" (Cayuela). 


\section{¿La guerra ha terminado?: ¿Qué revela de la España del siglo XXI?}

El filme de Semprún llega a ser un marco idóneo para la exposición, que responde al despotismo. Si bien el arte franquista ostenta una vertiente militante, o sea de propagar y esperar cierta reacción evocada del espectador (el sentimiento y celo ardiente por la nación), es importante señalar que la exposición ¿La guerra ha terminado? no espera ninguna reacción precisa del espectador, sino que aspira a despertar el raciocinio y la contemplación. Según explican Jesús Carrillo y Rosario Peiró, Jefe de Programas Culturales y Jefa de Colecciones de MNCARS respectivamente, los espacios de la exhibición evocan una "cata" o lecturas transversales que reflejen visiones personales, como hilos que guían por el laberinto de las complejidades del siglo XX (27). Si hubiera una meta concreta del conjunto de obras colgadas, instaladas y proyectadas en la cuarta planta del edificio Sabatini, sería la dinámica entre la obra y el visitante, el proceso de pensar, contemplar e intelectualizar con respecto a las ideologías que supeditan la humanidad a la ambición política. En Nations and Nationalism, Ernest Gellner dilucida que:

\footnotetext{
Nationalism is primarily a political principal, which holds that the political and national unit should be congruent [...] Nationalism as a sentiment, or as a movement, can best be defined in terms of this principle. Nationalist sentiment is the feeling of anger aroused by the violation of the principle, or the feeling of satisfaction aroused by its fulfillment. A nationalist movement is one actuated by a sentiment of this kind." (Gellner 1 )
}

El renombrado director de la industria cinematográfica española de los años 30 y 40, Florián Rey ${ }^{10}$ explaya su afán por despertar ardor en el público nacional mediante el musical folclórico español: "la españolada contiene, en germen, lo español, este substrato nacional, ese elemento imponderable que hace al público solidarizarse de un modo caliente y absoluto" (Gubern citado en Ruiz Muñoz y Sánchez Alarcón 36). Cabría decir, con la ideología nacionalista. O 
sea, dicho de otra manera, la españolada-debatiblemente la quintaesencia del arte popular nacionalista-evoca una emoción, ${ }^{11}$ un sentido de unidad con los compatriotas.

Aunque la reacción evocada por las obras del MNCARS aquí estudiadas dista de la reacción deseada por el arte nacionalista, al indagar en la cuestión de intelectualización y la sensibilidad, he de subrayar que rechazo el dualismo cartesiano que diametralmente contrapone la emoción y el raciocinio. Según explica Antonio Damasio en Descartes' Error: Emotion, Reason and the Human Brain, la emoción tiene un impacto en el razonamiento lógico, es decir, resulta imposible separar la lógica de la capacidad humana de sentir. Para Damasio, la racionalidad constituye "the quality of thought and behavior that comes from adapting reason to a personal a social context" (78-79). Sin embargo, como nos recuerda este neurocientífico, "Biological drives and the automated somatic-marker mechanism [...] can be pernicious to rational decision-making in certain circumstances by creating an overriding bias against objective facts or even by interfering with support mechanisms of decision making such as working memory" (191-192). El nacionalismo-ya sea el movimiento o el arte-se basa en el sentimiento que resulta de un sesgo dominante: la homogeneizada unidad nacional.

Con respecto a las obras antifranquistas aquí estudiadas, la manera por la cual la sensibilidad estética se compenetra con el razonamiento intelectual dista en gran medida del efecto deseado inherente al arte fascista. La producción cultural fascista o nacionalista aspira a evocar el celo, el ardor, la emoción sesgada, o sea, la unidad nacional descrita por Gellner, o la solidaridad caliente y absoluta elaborada por Florián Rey. El arte fascista es un estímulo heterónomo (es decir, viene de afuera) ${ }^{12}$ que tiene como fin una experiencia homogeneizante: el celo nacional compartido. En las obras de Semprún, Resnais, Genovés, Tàpies y Arroyo coexisten la razón y la sensibilidad. Las obras estimulan el pensamiento y respuestas somáticas ${ }^{13}$ de sus espectadores 
individuales. Estas constituyen experiencias subjetivas, individualizadas y, sobre todo, autónomas. Lo subjetivo y la subjetividad no han de considerarse antitéticos a lo intelectual. El razonamiento intelectual es subjetivo y no excluye la posibilidad de sentir. Las pinturas y el film no dictan respuestas, sino que hacen preguntas. No proporcionan clausura, sino que abren un diálogo e invitan a la indagación en su significado.

\section{Las obras}

Las cuatro pinturas españolas de los sesenta que seleccioné de ¿La guerra ha terminado? afirman, desmienten y/o dialogan con el coetáneo texto fílmico que da título a la exposición. Al igual que el filme, todas son de un creador español de renombre y de mediados de la década. Blau amb quatre barres roges (1966) de Antoni Tàpies (Barcelona 1923-2012), alude implícitamente a la colaboración franquista-hitleriana y los campos nazis, en los cuales estuvo internado Semprún. Los cuatro dictadores (1963) de Eduardo Arroyo (Madrid 1937), por ubicarse en la sala 428 , constituye un preludio a la sala 429 titulada "La guerra ha terminado" donde se exhiben La puerta (1966) de Juan Genovés (Valencia 1930), y España te miró (1967) de Arroyo. De hecho, cuando se inauguró la exposición, La puerta y España eran las únicas obras que se exhibían en la sala con el filme y daban fin al recorrido.

\section{Blau amb quatre barres roges}

Pasemos ahora a comentar el óleo y arena sobre lienzo $(169,9$ x 195,3 cm) del artista catalán Antoni Tàpies. El título (en catalán) Blau amb quatre barres roges (Azul con cuatro barras rojas) resulta ambiguo. Las cuatro barras representadas parecen aludir a las rayas raspadas por un preso con el fin de cuantificar su existencia y a su vez para conferirle significado a su encarcelamiento. Además, las cuatro barras rojas, para un barcelonés, podrían aludir a la bandera catalana. Según Xavier Antich y Carles Guerra, estas barras aluden no solo a la bandera 
prohibida aún en 1966, sino también a la Caputxinada, o sea el movimiento anti-franquista universitario en que participó Tàpies mismo y por el cual fue detenido. Las gafas en el centro empiezan a desaparecer, recordando a las conocidísimas imágenes de los efectos personales arrebatados a presos, internos y deportados. Antich y Guerra hacen hincapié en que las gafas y el ojo de perfil invitan a la mirada, el escrutinio crítico. La cara a la izquierda de la primera barra roja, al igual que las gafas, se esfuma. A la derecha de las barras rojas aparece una raya horizontal con cinco rayas diagonales; resulta reminiscente de una cicatriz, la evidencia del trauma vivido. El azul del título, apenas visible en el cuadro, nos hace cuestionar su significado: azul, el matiz de la división de 47.000 voluntarios franquistas que lucharon para los nazis en el frente ruso, el color de los nacionales y, por supuesto, el tono del triángulo que llevaban los españoles en los campos nazis, además del nombre de la Asociación para los catalanes deportados a los campos de concentración: Triangle Blau. A partir de obras como Figura de paper de diari i fils (1946), Tàpies coloca la materia como protagonista en sus obras, una decisión que imbuye la materia misma de sentido simbólico. Su producción posterior forja un espacio pictórico nuevo "concebido como lugar que invita a pensar sobre la apariencia de la realidad. Tàpies anula todas las categorías formales en favor de una representación en la que no hay diferencias entre la materia y la forma: no trata de expresar una idea en un medio tradicional, sino que el propio medio sea la expresión de la idea" (MNCARS, Figura). La pintura matérica incorpora materiales "pobres"14 como la arena y da fe de la violencia técnica de tajar y romper la superficie de la obra misma. De ahí, Tàpies ejemplifica de manera plástica la analogía que presenta Naomi Diamant con respecto a la memoria narrativa-literaria del Holocausto. Igual que un caleidoscopio, la memoria se fragmenta, aparece y desaparece en dispares configuraciones, presentando así un conjunto hecho y rehecho de los mismos fragmentos (207). De modo parejo a Semprún en La guerre est finie, pero especialmente en lo que se puede considerar sus novelas 
de campos de concentración (Le grand voyage, L'écriture ou la vie), Tàpies, también antifranquista, activista y preso, construye una inefable narrativa memorialista repleta de valor sensorial, emotivo y estético que divaga por los senderos del pasado, deambulando fantasmalmente entre los intersticios de la presencia-ausencia y el presente incapaz de exorcizar el pasado traumático. Tàpies contrapone un símbolo del nacionalismo regional con el matiz de la persecución, pero a fin de cuentas su obra pone de manifiesto la celebración de autenticidad que va indisolublemente ligada a la represión posbélica.

\section{Los cuatro dictadores}

Eduardo Arroyo, de modo semejante a Semprún, Tàpies y Genovés, asumió una postura antifranquista tanto en su vida como en su producción cultural. Arroyo, artista multidisciplinar madrileño que vivió en el exilio desde 1958, se ha dedicado no solo a las artes plásticas (pintura, escultura, litografía, ilustraciones, carteles), sino también al teatro (como escenógrafo y dramaturgo) y la literatura. Este gran exponente de la figuración es conocido por su arte contestatario, provocador y beligerante. Su producción artística presenta una crítica punzante y mordaz, ya sea de las costumbres según revela Caballero español (1970) o del autoritarismo. Los cuatro dictadores no solo mutila y desentraña macabramente a los sujetos de su crítica dentro de los bordes del lienzo, sino que la obra en sí, al igual que el Guernica, funciona como emblema de la iconografía antifascista. Al presentarse el políptico en 1963 en la III Bienal de París, el gobierno franquista protestó. Cuando se exhibió en Madrid el siguiente año, se censuró y el artista huyó por temor a ser detenido. Según Antonio Lucas, “Desde los años 60 [...] estableció un discurso lúdico, febril, autónomo y potencial donde asume el arte como un acontecimiento urticante, un espejo ácido, una mirada zotal ante un presente que repite sus vicios y malformaciones" (Lucas). Los cuatro dictadores pone de manifiesto "las vísceras" 15 literal y metafóricamente de cuatro dictadores 
totalitarios del siglo XX: Franco, Mussolini, el portugués Salazar y Hitler. Este políptico cuatripartito de orientación horizontal (óleo sobre lienzo, 235 x 560 $\mathrm{cm}$ ) se divide en cuatro partes iguales-una para cada líder totalitario. El trasfondo de cada retrato (cabeza, tórax y abdomen) consta de las franjas de las respectivas banderas nacionales. Las cabezas quedan desenmascaradas de la cara, dejando a plena vista las maquinaciones, motivos e influencias (el Papa, la matanza, la muerte). Curiosamente, todos menos Salazar están uniformados, enfatizando que el jefe de estado también era el jefe militarque exigía control a toda costa mediante la fuerza. Si el arte totalitario, con su iconografía, es monumental y ostenta el propósito de ocultar la bajeza y el genocidio, el políptico de Arroyo desmiente la singularidad de II Duce, Der Führer y el Caudillo, y los iguala, subvirtiendo los emblemas que empleaban para enaltecer su ideología. Además, al yuxtaponerlos subraya la colaboración que posibilitó las deportaciones y el genocidio.

\section{La puerta}

Juan Genovés, ${ }^{16}$ artista plástico destacado por su antifranquismo durante el régimen, posteriormente emblematizó la reconciliación de la Transición con su conocidísima obra El abrazo (1976), cuyo original se ubica en el Reina Sofía, mientras que su réplica se halla en el Congreso de los Diputados. Esta obra sirvió como imagen para un cartel de la ONG Amnistía Internacional y también inspiró la escultura homónima en 2003 que homenajea los abogados laboralistas asesinados por la extrema derecha en la calle Atocha en 1977 (García; Hernando). Actualmente, desde una perspectiva izquierdista, el valor de El abrazo radica en su simbolización "de un tiempo que aún sigue estando presente en la memoria colectiva" (Hernando). En los años sesenta aparecen en las obras de Genovés "Ios símbolos de la violencia política", "el realismo de la alambrada", "la crueldad de la culata de los fusiles", "la dialéctica del miedo", y la "soledad del individuo en medio de la multitud", además de 
criaturas que corren (Vicent). Genovés decía que después de desbordar los límites del lienzo, "sus criaturas no paraban de correr hasta encontrar un sueño de paz, justicia y armonía” (Vicent). De manera paralela a Blau, La puerta de Juan Genovés, explora los temas del trauma, la persecución y el genocidio. Esta obra comparte la sala 429 con el filme de Semprún y España te miró de Arroyo.

La puerta (pintura de técnica mixta sobre lienzo, $140 \times 90 \mathrm{~cm}$ ) se divide en dos partes, la superior y la inferior, que captan el momento antes y después de una masacre. La puerta que domina la composición resulta ambivalente. No se sabe si la muchedumbre está excluida de lo que hay al otro lado de la puerta y se le prohíbe salir o si está encerrada, atrapada a este lado. No obstante, queda claro, por los cadáveres en la parte inferior que unas violentas fuerzas hegemónicas dispersaron a los que aguardaban para pasar por la puerta. Del mismo modo que las imágenes intersticiales del filme, La puerta de Genovés pone de manifiesto la interacción y la situación precaria de los que se encuentran en la frontera de dos realidades, ya sea el exilio interior o exterior, la condición de apátrida indeseable o la de enemigo doméstico.

\section{España te miró}

Por último, analicemos otra obra de Arroyo que comparte sala con La puerta de Genovés y el filme de Semprún. España te miró está repleta de intertextos artísticos: la fragmentación del desnudo femenino recuerda a Les demoiselles d'Avignon de Picasso, pero también a su Guernica. La cara del desnudo viene de La maja de Goya, que parece mimetizar, hasta cierto punto, la Venus del espejo de Velázquez. El espejo pone de relieve la triple mirada: la del sujeto, la de su reflejo y la del espectador. Es factible que el desnudo, mediante el espejo, sostenga la mirada del espectador. Mediatizada esta por el reflejo del espejo, resulta incierto si la mujer mira al espectador o se mira a sí misma. La figura desnuda de Arroyo está sentada en un taburete tapizado 
con la imagen cartográfica de España y rodeada de la tricolor republicana, mientras la alfombra (o el suelo) ostenta la bandera monárquica y franquista, repetida y divida por franjas azules. Ahora bien, nos preguntamos cuál es el significado del título, especialmente con respecto a su relación física con el filme de Semprún. ¿Quién o qué es España? ¿Es la República en el exilio, son los españoles en Francia como muchos ex-deportados o refugiados o exiliados, como Semprún o Arroyo mismo cuando pintó el cuadro? ¿A quién se refiere el pronombre reflexivo "te"? Ya que la maja recontextualizada sujeta un espejo, si se mira a sí misma, constituye una mirada reflexiva. Sería una especie de desdoblamiento, una entidad que dialoga consigo misma. Si "te" apela directamente al espectador, a quien clava la mirada como si estuviera en un espejo retrovisor, resulta una mirada desafiante y urticante, una invitación a interactuar con ella. La obra, entonces, resulta ser una exhortación a ponderar complejidades, atrocidades y realidades del pasado con miras hacia el futuro a la luz de la unidad e Historia oficial impuestas durante casi cuarenta años de dictadura. ${ }^{17}$

\section{Conclusiones}

Para concluir, aunque las pinturas y el filme empleen métodos dispares (es decir, la eliminación de símbolos nacionales vs. su recontextualización), el efecto es el mismo: el cuestionamiento de los emblemas que supuestamente representan una ideología y una identidad, propagadas e impuestas durante las décadas posbélicas. Sin lugar a dudas, todas las obras estudiadas denuncian los fascismos de toda estirpe y proponen una gran interrogativa: ¿quiénes somos dentro del contexto posbélico, postraumático y posdictatorial, pero también posdemocrático? La descripción de La guerre est finie concluye con el motivo de su selección como marco contextualizador de la colección y final del recorrido: por ser el "retrato de la paulatina desaparición de los fantasmas de la guerra y del despertar a un presente lleno de incertidumbres" (¿La guerra 
ha terminado?). El espectador de nuestra década del siglo XXI que contempla estas obras de los años 60-y que ve en las noticias a diario los vestigios y el legado del franquismo, ya sea, por ejemplo, mediante la exhumación de fosas yuxtapuesta a una controvertida exposición de artefactos nacionales y nazis¿cómo se puede aproximar a los espectros del franquismo y los fantasmas hauntologiques $^{18}$ de la guerra si siguen entre nosotros? Puede que no sea factible exorcizarlos, pero el arte, sin lugar a dudas, posibilita encararlos.

El filme de Semprún y Resnais constituye el marco contextualizador de la exposición permanente ¿La guerra ha terminado? que concientiza e invita a examinar de diversas maneras los múltiples fenómenos deshumanizantes de mediados del Siglo XX. El conjunto que forman el filme del escritor madrileño, expreso de los nazis, y las cuatro obras descritas presenta un testamento de escrutinio del fascismo y a su vez una subversión del arte nacionalista. Mientras que el arte nacionalista exalta la gran nación y su líder, inspirando celo, neutralizando el intelecto y evocando una singular mentalidad colectiva, la exposición ¿La guerra ha terminado?: El arte en un mundo dividido (19451968)? desmitifica y desenmascara a los líderes fascistas (como revela Los cuatro dictadores de Arroyo), pluraliza y cuestiona la identidad (según vemos en España te miró), rechazando así la imposición heterónoma, denuncia el genocidio (como indican La puerta y Blau amb quatre barres roges) y, sobre todo, exige la intelectualización y la crítica como elementos esenciales a la libertad de pensamiento. En otras palabras, la exposición, clausurada con el filme de Semprún, quiebra y hace añicos la monolítica ideología indoctrinada (y su concomitante estética nacionalista) para revelar la pluralidad, fragmentación y diversidad de pensamiento que conlleva la plena democracia. Esta exposición es única. Revela el empeño descrito por Baer y Sznaider con respecto a los esfuerzos memorialistas contemporáneos, metaforizados por el Angelus Novus, el ángel de la historia, 
"an unwelcome messenger who will alter perception and make us attentive to the dark flipside of a factuality that is built on ruins [...] What we deem progress in a modernized Spain — the subsequent waves of economic development built upon in the 1960s - has its roots in unspeakable barbarity. The time of memory questions that of history" (78).

Ya en el Siglo XXI con la polémica y, quizá polarización, entre memoria y olvido, esta colección permanente sirve de constante recordatorio de que no es la pluralidad de perspectivas-producto de la libertad-lo que amenaza a la sociedad y la humanidad, sino que es la imposición de un falso sentido de unidad y uniformidad lo que da pie a las atrocidades impensables, indecibles e increíbles que atestiguó el siglo XX.

\section{Notas}

1 De Alemania, Argelia, Bélgica, Brasil, Bulgaria, Egipto, España, Estados Unidos, Francia, Italia, Reino Unido, Suecia, Suiza, Venezuela, entre otros.

2 Un ejemplo de una obra no española que evoca el pensamiento crítico es el filme-performance de Öyvind Fahlström titulada Mao-Hope March en que capta en película la manifestación callejera organizada por el artista en la Quinta Avenida (Nueva York). Los manifestantes llevaban carteles de Mao Tse Tung y del cómico Bob Hope. Paseantes fueron entrevistados con la pregunta “¿Es Ud. feliz?” así aludiendo a la constitución de EE.UU. y la premisa occidental de gozar de la libertad de buscar la felicidad, y poniendo en tela de juicio la factibilidad de la felicidad como meta de la libertad al yuxtaponerse con la imagen del líder chino.

3 Se puede realizar una visita virtual en http://www.museoreinasofia.es/coleccion/ coleccion-2-la-guerra-ha-terminado-arte-en-un-mundo-dividido. Blau se ubica en la sala 417, Los cuatro dictadores en la 428 y la sala 429 "La guerra ha terminado" incluye La puerta, España te mira y La guerre est finie.

4 Ha de entenderse que, entre la realización de este análisis y la lectura del artículo que el lector tiene entre manos, la obras pueden haberse reubicado. Este estudio capta un momento particular en el MNCARS y, de ahí, refleja la naturaleza efímera de una exposición, aunque las obras formen parte de la colección permanente. Para la conceptualización concreta que respecta a la apertura de la exposición 
permanente, véase Is the War Over?: Art in a Divided World (1945-1968) publicada por el MNCARS en el 2010.

5 Resulta imprescindible subrayar que, aunque no participe exclusivamente en el esfuerzo español por recuperar de la memoria histórica, la colección se exhibió durante el gobierno de José Luis Rodríguez Zapatero que proclamó la Ley de Memoria Histórica (2007) y una década después de fundarse la Asociación para la Recuperación de la Memoria Histórica.

6 Las galerías se distinguen entre sí. Por una parte, ciertas obras, como las de Fahlström indagan en los conflictos bélicos entre oriente y occidente, mientras que la colección de fotografía en blanco y negro de Andalucía (por ejemplo la serie "Sevilla 1950" de Brassaï o "Pueblos españoles" de Eugene Smith) captan la paradoja del aislamiento de la España posbélica y su apertura al turismorevelándose exótica y pintoresca con las andaluzas de negro en un velorio, estatuillas de penitentes en un escaparate y una sevillana de negro cargando su bata de cola al hombro.

7 “l'Histoire et la lutte contre les forces d'oppression et de mort” (13).

8 “To hear you talk, no one would ever guess you're Spanish" (Guerre 17).

9 “[Diego]: Poor unhappy Spain, heroic Spain, I've had enough of Spain, more than enough. Spain's become a [...] myth for veterans of past wars. Meanwhile fourteen million tourists go to Spain every year on vacation. All Spain is any more is a tourist's dream, or the myth of the civil war. [...] Spain isn't the dream of '36 any longer" (Guerre 93-94).

10 Florián Rey-junto con Benito Perojo—se consideraban los directores "mejor formados de la industria cinematográfica nacional" (Ruiz Muñoz y Sánchez Alarcón 29).

11 Como la ira que describió Gellner respecto al sentimiento nacionalista.

12 Utilizo los términos "heterónomo" y "autónomo" de manera paralela a su uso en la psicología moral. La moralidad autónoma es individualizada y es producto del razonamiento moral, mientras que la moralidad heterónoma resulta de la interiorización de un código predeterminado e impuesto.

13 Damasio se refiere a la manifestación física de la emoción como "marcadores somáticos".

14 Aludiendo al movimiento italiano del Arte Povera.

15 Antonio Lucas discierne que "la figuración 'visceral' fue su [de Arroyo] territorio". 
16 Falleció el 15 de mayo de 2020 mientras se estaban haciendo los últimos toques a este artículo.

17 No es hasta 2015 que la Real Academia de Historia reconoció a Francisco Franco como dictador.

18 Teoría que Jacques Derrida desarolla en Spectres of Marx.

\section{Obras citadas}

Aguado, Txetxu. "Dissidence, Citizenry, and Witnessing: Three Screenplays by Jorge Semprún." A Critical Companion to Jorge Semprún: Buchenwald Before and After, editado por Gina Herrmann y Ofelia Ferrán, Palgrave, 2014, pp. 187-202.

Antich, Xavier, y Carles Guerra. Tàpies: Biografia d'un compromís. Grup Enciclopèdia.

Asociación Cultural Libre Configuración. “¿La guerra ha terminado? Arte en un mundo dividido (1945-1968).” Lcmagazine, Fecha de acceso: 6 feb. 2015.

Baer, Alejandro, y Natan Sznaider. Memory and Forgetting in the Post-Holocaust Era. Routledge, 2017.

Bhabha, Homi. The Location of Culture. Routledge, 1994.

Borja Villel, Manuel. "At the End of Utopia." Is the War Over?: Art in a Divided World (1945-1968), editado por Sonsoles Espinós, Amaia Múgica y Ruth Gallego, MNCARS, 2010, pp. 5-9.

Carrillo, Jesús, y Rosario Peiró. "Introduction.” Is the War Over?: Art in a Divided World (1945-1968), editado por Sonsoles Espinós, Amaia Múgica y Ruth Gallego, MNCARS, 2010, pp. 13-27.

Cayuela Gally, Ricardo. "Entrevista con Jorge Semprún: La memoria como escritura." Letras Libres, año 5, núm. 60, diciembre 2003, pp. 37-42.

Damasio, Antonio. Descartes' Error: Emotion, Reason and the Human Brain. Penguin, 2005. Primera edición 1994.

Diamant, Naomi. The Boundaries of Holocaust Literature: The Emergence of a Canon. 1992. Columbia University, PhD Dissertation.

Espinós, Sonsoles, Amaia Múgica, y Ruth Gallego, editoras. Is the War Over?: Art in a Divided World (1945-1968). MNCARS, 2010.

Faber, Sebastiaan. “¿Usted, qué sabe?: History, Memory and the Voice of the Witness." Revista Canadiense de Estudios Hispánicos, vol. 36, no. 1, otoño 2011, pp. 9-27. 
Ferrán, Ofelia. “'Cuanto más escribo, más me queda por decir:' Memory, Trauma, and Writing in the Work of Jorge Semprún." MLN, vol. 116, no. 2, Hispanic Issue, mar. 2001, pp. 266-94.

Ferrán, Ofelia, y Gina Herrmann, editoras. A Critical Companion to Jorge Semprún: Buchenwald Before and After. Palgrave, 2014.

—. "Introduction." A Critical Companion to Jorge Semprún: Buchenwald Before and After, editado por Ofelia Ferrán y Gina Herrmann, Palgrave, 2014, pp. 1-36.

García, Ángeles. “Muere Juan Genovés, el defensor del arte como abrazo.” El País, 15 may. 2020, http://elpais.com/cultura/2020-05-15/muere-el-pintor-juan-genovesel-artista-que-retrato-a-las-multitudes.html Fecha de acceso: 15 mayo 2020.

Gellner, Ernest. Nations and Nationalism. Cornell UP, 1983.

¿La guerra ha terminado?: El arte en un mundo dividido (1945-1968). Exposición permanente, MNCARS, Madrid. http://www.museoreinasofia.es/coleccion/ coleccion-2-la-guerra-ha-terminado-arte-en-un-mundo-dividido

La guerre est finie. Dirigido por Alain Resnais, Guion de Jorge Semprún, Europa Film, 1966, DVD.

Hernando, Silvia. “'El abrazo’ que fue símbolo de la Transición.” El País, 15 may. 2020, http://elpais.com/cultura/2020-05-15/el-abrazo-que-fue-simbolo-de-la-transicion. html. Fecha de acceso: 25 jul. 2020.

Kaplan, Brett Ashley. Unwanted Beauty: Aesthetic Pleasure in Holocaust Representation. U of Illinois P, 2007.

Llorente Hernández, Ángel. Arte e ideología en el franquismo (1936-1951). Visor, 1995.

Lucas, Antonio. "Muere Eduardo Arroyo, el último león de lafiguración."

El Mundo, 14 octubre 2018, https://www.elmundo.es/cultura/2018/10/14/ 5bc31d3f268e3e0c668b4574.html. Fecha de acceso: 16 de septiembre 2020.

Miletic, Tijana. "The Significance of Art in Semprún's Writing." Critical Companion to Jorge Semprún: Buchenwald Before and After, editado por Ofelia Ferrán y Gina Herrmann, Palgrave, 2014, pp. 169-84.

Nicoladzé, Françoise. La deuxième vie de Jorge Semprún: Une écriture tressée aux spirale de l'Histoire. Climats, 1998.

Nuit et brouillard. Dirigido por Alain Resnais, Argos Films, 1956, DVD. 
Ruiz Muñoz, María Jesús, e Inmaculada Sánchez Alarcón. La imagen de la mujer andaluza en el cine español. Centro de Estudios Andaluces, 2008.

Semprún, Jorge. La escritura o la vida. Tusquets, 1995.

—. La guerre est finie. Paris, 1966.

—. El largo viaje. Tusquets, 2004. Edición Gallimard 1963.

—. Mal et modernité: Le travail de l'histoire. Climats, 1990. Discurso presentado en la Sorbona el 19 de junio de 1990.

Tobin Stanley, Maureen. "El tránsito, el transporte y la trascendencia: El exilio y la deportación en Jorge Semprún.” El exilio republicano de 1939 y la segunda generación, editado por Manuel Aznar y José Ramón López García, Sevilla, Renacimiento, 2011, pp. 590-97.

Vernon, Kathleen. "The Trauma of History/The History of Trauma: Plotting Memory in Jorge Semprún." Cine-Lit III: Essays on Hispanic Film and Fiction, editado por George Cabello-Castelet, Jaume Martí-Olivella y Guy Wood, Oregon SU, 1998, pp. 157-67.

Vicent, Manuel. “Juan Genovés: El sueño interminable.” El País, 15 may. 2020, http:// elpais.com/cultura/2020-05-15/juan-genoves-el-sueno-interminable.html Fecha de acceso: 15 may. 2020.

\section{Obras de arte}

El abrazo (1976) de Juan Genovés

Blau amb quatre barres roges (1966) de Antoni Tàpies

Caballero español (1970) de Eduardo Arroyo

Los cuatro dictadores (1963) de Eduardo Arroyo.

España te miró (1967) de Eduardo Arroyo

Figura de paper de diari i fils (1946) de Antoni Tàpies

Monument aux espagnols morts pour la France (1946-47) de Pablo Picasso

La puerta (1966) de Juan Genovés

¿La guerra ha terminado? (acceso virtual) http://www.museoreinasofia.es/coleccion/ coleccion-2-la-guerra-ha-terminado-arte-en-un-mundo-dividido 